\title{
Not miR-ly muscular: microRNAs and muscle development
}

\author{
Julius Brennecke, Alexander Stark, and Stephen M. Cohen ${ }^{\mathbf{1}}$ \\ European Molecular Biology Laboratory, 69117 Heidelberg, Germany
}

Precision in spatial and temporal control of gene expression is important for formation of tissues and organs. Roughly $5 \%$ of the known gene complement in animals encodes transcriptional activators and repressors, whose combinatorial action controls the expression of target genes, triggering cell-fate decisions and differentiation during development. With the discovery of microRNAs, a new means of regulating gene expression has been introduced (for review, see Lai 2003; Ambros 2004; Bartel 2004). These 22 -nucleotide-long RNAs are now thought to comprise $1 \%-5 \%$ of the known genes in organisms ranging from nematodes and flies to mammals (Bartel 2004; Berezikov et al. 2005; Xie et al. 2005). microRNAs have been shown to act as negative regulators of target gene expression by recruiting silencing complexes to complementary sequence elements in target mRNAs. Bioinformatic studies have demonstrated that the average animal miRNA has hundreds of target genes, so that up to $30 \%$ of all animal genes are miRNA targets (Brennecke et al. 2005; Grün et al. 2005; Krek et al. 2005; Lewis et al. 2005; Xie et al. 2005). Considering that target sites often occur in a combinatorial fashion, these findings suggest an enormous regulatory potential for miRNAs in gene expression programs, rivaling the complexity of the transcriptional control network. But what do they do?

miRNAs are expressed in essentially every cell type analyzed to date. A recent systematic analysis of spatial expression of miRNAs in zebrafish larvae showed that most, if not all, tissues and organs express a unique miRNA complement (Wienholds et al. 2005). Not surprisingly, individual miRNAs have been implicated in a variety of developmental and physiological processes, including control of developmental timing, cell proliferation, cell fate specification, apoptosis, morphogenesis, fat metabolism, insulin secretion, and cancer (Lee et al. 1993; Wightman et al. 1993; Reinhart et al. 2000; Brennecke et al. 2003; Johnston and Hobert 2003; Xu et al. 2003; Chen et al. 2004; Esau et al. 2004; Poy et al. 2004;

${ }^{1}$ Corresponding author.

E-MAIL cohen@embl.de; FAX 49-6221-387166.

Article and publication are at http://www.genesdev.org/cgi/doi/10.1101/ gad. 1363905
Giraldez et al. 2005; He et al. 2005; Johnson et al. 2005; $\mathrm{Lu}$ et al. 2005). However, in most of these studies, the actual role of the miRNA in these processes is fairly unclear. A few of these functions have been attributed on the basis of a miRNA loss-of-function mutant phenotype. Others are inferred from the effects miRNA overexpression or misexpression. Given their numerous targets and spatially limited expression patterns, ectopic expression of miRNAs can be expected to cause phenotypes, due to down-regulation of potential target genes in the tissue where the miRNAs are not normally expressed. How well do these reflect the endogenous function of the miRNA? In some cases miRNA misexpression has produced phenotypes essentially reciprocal to the loss-of-function mutant. Premature let-7 and lin-4 expression cause precocious development, while their mutants cause developmental retardation in Caenorhabditis elegans (Lee et al. 1993; Reinhart et al. 2000). bantam overexpression causes tissue overgrowth, whereas the mutant causes undergrowth in Drosophila (Brennecke et al. 2003). In other cases, the reciprocity is less clear (Xu et al. 2003) and for most others it has not been examined for lack of mutants.

In this issue of Genes \& Development, Sokol and Ambros (2005) have made an important step forward through the characterization of a miR-1 mutant in Drosophila. This study considerably advances our understanding of animal miRNA genes, in part because its key result is somewhat unexpected. $m i R-1$ is among the most highly conserved miRNAs and is found in nematodes, flies, and all vertebrates analyzed so far, where it is specifically expressed in muscle tissue (Mansfield et al. 2004; Sokol and Ambros 2005; Wienholds et al. 2005; Zhao et al. 2005). On this basis, it was perhaps expected that miR-1 mutants would play a major role in muscle patterning or differentiation. Yet surprisingly, $m i R-1$ mutants develop normal functional muscles and show muscle defects only later in development. The Sokol and Ambros paper provides new insight into the role of $m i R-1$ and serves to illustrate general issues that pertain to understanding miRNA functions in vivo.

Together with recent reports on vertebrate embryos (Wienholds et al. 2005; Zhao et al. 2005), Sokol and Ambros' (2005) findings illustrate some interesting com- 
monalities and differences in $m i R-1$ expression and function. In mouse, zebrafish, and flies, miR-1 is a mesodermally expressed miRNA that accumulates in various muscles. In all cases, it is highly expressed in the somatic musculature. However, whereas fly and mouse $m i R-1$ genes are expressed in the developing heart, this does not appear to be a site of obvious miR-1 expression in the zebrafish. Conversely, the head musculature expresses miR-1 in flies and fish, but not in mouse. Differences are also seen in the onset of miR-1 expression. Fly miR-1 is among the earliest detectable miRNAs and its transcription is activated in a broad pan-mesodermal domain prior to gastrulation and it continues to be expressed in nascent and differentiating muscle throughout development. In contrast, the two mouse miR-1 genes and zebrafish miR-1 are first detected considerably later, at the beginning of muscle differentiation. Key muscle-specific transcription factors control miR-1 expression in flies and mice. In flies, the early mesodermal expression of $m i R-1$ appears to be exclusively regulated by twist, while its later expression-restricted to the somatic and visceral musculature and the heart-requires $d M e f-2$. In mouse, the two miR-1 genes are under the control of SRF-myocardin-dependent pathways in heart precursor cells, while being responsive to MyoD and Mef2 in skeletal muscles. These similarities suggest that miR-1 evolved as a mesodermal/muscle-specific miRNA early in animal evolution, but that it has been integrated subsequently into the hierarchy of muscle transcription networks in different ways. In particular, the temporal differences in miR-1 expression raises questions about the nature of the genes that miR-1 regulates in different species and the extent to which we should expect its function to be comparable.

Sokol and Ambros (2005) show that absence of miR-1 during fly development leads to a highly penetrant lethal phonotype during larval development. Presence of a genomic fragment containing the full miR-1 locus as well as expression of the $m i R-1$ precursor hairpin specifically in mesoderm and muscle led to a full rescue of the lethal phenotype. This not only attributes the phenotype specifically to $m i R-1$ but also indicates that miR-1 function is required only in mesodermal/muscle cells, consistent with its expression pattern. Strikingly, the muscle system of mutant embryos seems to develop normally. Eighty percent of mutant embryos hatched as motile larvae and the remaining $20 \%$ did not show discernable muscle or heart defects (N. Sokol, pers. comm.). As there is only a single miR-1 gene in flies, this shows that miR-1 does not participate in crucial decisions regarding muscle patterning or differentiation. This conclusion is difficult to reconcile with the results of another recent report in which miRNA function was ablated by injection of antisense 2'O-methyl oligoribonucleotides into early Drosophila embryos (Leaman et al. 2005). Previous reports have shown that 2'O-methyl oligoribonucleotides effectively block miRNA function (Hutvagner et al. 2004; Meister et al. 2004; Poy et al. 2004). Leaman et al. (2005) reported that injection of miR-1 complementary 2'O-methyl oligoribonucleotides resulted in substantial embryonic lethality, with few survivors and severe defects in embryonic morphology. Although suitable controls were performed, there appears to be a substantial difference between these results and those generated by the mutant. As Sokol and Ambros' (2005) experiments excluded the possibility of a maternal contribution of miR-1 to the embryo, the basis for the discrepancy between the injection assay and the mutant phenotype remains to be explained.

Lacking an overt muscle defect, Sokol and Ambros (2005) went on to explore muscle function. Careful examination showed that the somatic musculature and the heart were apparently fully functional. Furthermore, they excluded that the lethality was caused by defects in feeding or food transport in the digestive tract. However, as soon as mutant animals started to feed, they became paralyzed, arrested growth, and died with massively disrupted larval body musculature. Interestingly, prolonged normal muscle function was possible in mutants kept alive on a sugar diet to provide energy, while blocking the normal larval growth phase. This indicated that the basic contractile function and physiology of the muscle system is apparently fine in the mutants. Muscle defects emerged only after the animals began the rapid phase of larval growth that begins with feeding on a normal protein-rich diet. During $4 \mathrm{~d}$ of development, Drosophila larvae grow 200-fold. This phase of growth depends on endoreplication, an altered cell cycle in which the DNA duplicates, but without mitosis, so that ploidy increases and cells grow larger without dividing. Blocking the endocycle by other means leads to growth arrest, but does not affect muscle integrity.

Given its highly specific expression pattern in muscle tissue, the absence of a defect during embryonic muscle development in miR-1 mutants was unexpected-and raises many questions for future work. Unlike the classical nematode miRNAs let-7 and lin-4, there seems to be a very long lag between the onset of miR-1 expression and the first evidence of a muscle defect in $m i R-1 \mathrm{mu}$ tants. How does the absence of miR-1 cause muscle degeneration during larval growth? Does this reflect subtle errors in cell-fate specification caused by failure to repress one or more miR-1 target genes during embryogenesis, which only become apparent under conditions of rapid growth? Is $m i R-1$ specifically required during the larval growth phase, perhaps coordinating the endoreplication of muscle cells, or preventing expression of genes that are systemically up-regulated during that growth phase but need to remain repressed in muscle? Does the miR-1 phenotype result from deregulation of a small number of important targets or from failure to maintain repression of the large numbers of predicted targets?

At least preliminary answers to these questions should reside in the identity of $m i R-1$ target genes. Bioinformatic studies in vertebrates and Drosophila have predicted at least 100 different target genes for miR-1 (Enright et al. 2003; Lewis et al. 2003; Stark et al. 2003; Grün et al. 2005; Krek et al. 2005; A. Stark, J. Brennecke, N. Bushati, R. Russell, and S.M. Cohen, in prep.). These 
include genes with a considerable diversity of functions, including transcriptional control, signal transduction, structural components of the cytoskeleton, enzymatic activity, vesicle transport, motor proteins, or epithelial polarity. Analysis of the predicted target genes reveals that they are transcribed and important primarily in organs or cell types other than muscle (Sokol and Ambros 2005; A. Stark, J. Brennecke, N. Bushati, R. Russell, and S.M. Cohen, in prep.). This is consistent with the findings of Lim et al. (2005) who found that ectopic expression of miR-1 in HeLa cells mainly affected expression of genes normally expressed at low levels in muscle. Interestingly, there is very little overlap among the predicted targets of miR-1 in vertebrates and Drosophila (our unpublished observation), suggesting that there need not be a common underlying target profile required for miRNA function. The commonality might be that most targets are not normally expressed in muscle.

How does the fly miR-1 mutant compare with what has been learned about miR-1 in vertebrates? Recent work on the two mouse miR-1 genes has generated considerable excitement about the possibility that miR-1 controls the balance between cardioblast proliferation and differentiation (Zhao et al. 2005). The transcription factor Hand2, which is essential for early cardioblast proliferation, was identified computationally as a possible miR-1 target and shown to be down-regulated by misexpression of miR-1 throughout the developing heart. Interestingly, although Hand2 is initially expressed throughout the heart tube, by day 9.5, Hand2 is transcriptionally down-regulated in the inner curvature of the right ventricle, where miR-1-2 is highly expressed (McFadden et al. 2000; Zhao et al. 2005). Thus, there might normally only be limited coexpression of miR-1 and Hand2. Misexpression of miR-1 throughout the developing heart clearly can cause a pronounced proliferation defect due to repression of Hand2. However, given their limited overlap in expression, perhaps it is premature to extrapolate from the misexpression experiment and conclude that miR-1 normally regulates proliferation by repression of $\mathrm{dHand} 2$ expression. Instead, miR-1 may support efficient Hand2 down-regulation that is primarily caused by an independent transcriptional mechanism. Analysis of mouse miR-1 mutants will be needed for a definitive conclusion.

In our view, the importance of the work reported here by Sokol and Ambros (2005) may well prove to reside in the conclusion that the ancient miR-1 gene in Drosophila is dispensable for overall muscle patterning and differentiation, despite its spectacular expression pattern. Instead, miR-1 might confer robustness to the identity and physiology of muscle cells. Based on the functions of the first miRNAs studied, let-7 and lin-4 (Lee et al. 1993; Reinhart et al. 2000), we have come to expect striking developmental switch-like functions for miRNAs. Do miRNAs generally act as discrete off switches for a small number of key developmental regulators, as suggested for miR-1 by the work of Zhao et al. (2005)? Might they instead fine-tune expression of many target genes? Or might they be used as temporal and spatial gatekeepers that block translation of promiscuously transcribed genes whose expression would be detrimental for the cell, as suggested by the work of Lim et al. (2005)? Whether less "spectacular" modes of action, such as controlling robustness of developmental processes, will prove to be the case for other miRNAs can only be answered by the analysis of more miRNA mutants. A hint may already have been provided by studies in zebrafish where loss of all miRNA production has surprisingly limited effects on patterning and tissue differentiation (Giraldez et al. 2005).

Understanding the role of miRNAs leads inevitably to the question of why certain gene expression events are targeted by miRNAs rather than by transcriptional repressors. What advantage does this mode of regulation confer? One possibility is that having two independent steps subject to regulation can confer a more precise control of gene expression than could be achieved by either alone. In addition, a role in de-noising transcription seems well suited for small RNAs that can regulate sets of genes that may not share a common mode of transcriptional regulation. By acting on a post-transcriptional level, miRNAs might contribute to clearing residual messages when cells with rapidly changing identity face the problem of removing their prior gene expression program. By blocking translation, miRNAs might accelerate switching off critical regulators in development. Interestingly, this mode resembles the role of miRNAs in plants, where miRNAs contribute to cell fate decisions by clearing the cell of mRNAs encoding transcription factors, which confer identity to the mother cell (Rhoades et al. 2002).

\section{References}

Ambros, V. 2004. The functions of animal microRNAs. Nature 431: 350-355.

Bartel, D.P. 2004. MicroRNAs: Genomics, biogenesis, mechanism, and function. Cell 116: 281-297.

Berezikov, E., Guryev, V., van de Belt, J., Wienholds, E., Plasterk, R.H., and Cuppen, E. 2005. Phylogenetic shadowing and computational identification of human microRNA genes. Cell 120: 21-24.

Brennecke, J., Hipfner, D.R., Stark, A., Russell, R.B., and Cohen, S.M. 2003. bantam encodes a developmentally regulated microRNA that controls cell proliferation and regulates the pro-apoptotic gene hid in Drosophila. Cell 113: 25-36.

Brennecke, J., Stark, A., Russell, R.B., and Cohen, S.M. 2005. Principles of microRNA-target recognition. PLoS Biol. 3: e85.

Chen, C.Z., Li, L., Lodish, H.F., and Bartel, D.P. 2004. MicroRNAs modulate hematopoietic lineage differentiation. Science 303: 83-86.

Enright, A.J., John, B., Gaul, U., Tuschl, T., Sander, C., and Marks, D.S. 2003. MicroRNA targets in Drosophila. Genome Biol. 5: R1.

Esau, C., Kang, X., Peralta, E., Hanson, E., Marcusson, E.G., Ravichandran, L.V., Sun, Y., Koo, S., Perera, R.J., Jain, R., et al. 2004. MicroRNA-143 regulates adipocyte differentiation. J. Biol. Chem. 279: 52361-52365.

Giraldez, A.J., Cinalli, R.M., Glasner, M.E., Enright, A.J., Thomson, J.M., Baskerville, S., Hammond, S.M., Bartel, D.P., and Schier, A.F. 2005. MicroRNAs regulate brain morphogenesis 
in zebrafish. Science 308: 833-838.

Grün, D., Wang, Y.-L., Langenberger, D., Gunsalus, K.C., and Rajewsky, N. 2005. microRNA Target predictions across seven Drosophila species and comparison to mammalian targets. PLoS Computat. Biol. 1: e13. [Epub June 24, 2005; DOI: 10.1371/journal.pcbi.0010013.]

He, L., Thomson, J.M., Hemann, M.T., Hernando-Monge, E., $\mathrm{Mu}$, D., Goodson, S., Powers, S., Cordon-Cardo, C., Lowe, S.W., Hannon, G.J., et al. 2005. A microRNA polycistron as a potential human oncogene. Nature 435: 828-833.

Hutvagner, G., Simard, M.J., Mello, C.C., and Zamore, P.D. 2004. Sequence-specific inhibition of small RNA function. PLoS Biol. 2: E98.

Johnson, S.M., Grosshans, H., Shingara, J., Byrom, M., Jarvis, R., Cheng, A., Labourier, E., Reinert, K.L., Brown, D., and Slack, F.J. 2005. RAS is regulated by the let-7 microRNA family. Cell 120: 635-647.

Johnston, R.J. and Hobert, O. 2003. A microRNA controlling left/right neuronal asymmetry in Caenorhabditis elegans. Nature 426: 845-849.

Krek, A., Grun, D., Poy, M.N., Wolf, R., Rosenberg, L., Epstein, E.J., MacMenamin, P., da Piedade, I., Gunsalus, K.C., Stoffel, M., et al. 2005. Combinatorial microRNA target predictions. Nat. Genet. 37: 495-500.

Lai, E.C. 2003. microRNAs: Runts of the genome assert themselves. Curr. Biol. 13: R925-R936.

Leaman, D., Chen, P.Y., Fak, J., Yalcin, A., Pearce, M., Unnerstall, U., Marks, D.S., Sander, C., Tuschl, T., and Gaul, U. 2005. Antisense-mediated depletion reveals essential and specific functions of microRNAs in Drosophila development. Cell 121: 1097-1108.

Lee, R.C., Feinbaum, R.L., and Ambros, V. 1993. The C. elegans heterochronic gene lin-4 encodes small RNAs with antisense complementarity to lin-14. Cell 75: 843-854.

Lewis, B.P., Shih, I.H., Jones-Rhoades, M.W., Bartel, D.P., and Burge, C.B. 2003. Prediction of mammalian microRNA targets. Cell 115: 787-798.

Lewis, B.P., Burge, C.B., and Bartel, D.P. 2005. Conserved seed pairing, often flanked by adenosines, indicates that thousands of human genes are microRNA targets. Cell 120: 1520.

Lim, L.P., Lau, N.C., Garrett-Engele, P., Grimson, A., Schelter, J.M., Castle, J., Bartel, D.P., Linsley, P.S., and Johnson, J.M. 2005. Microarray analysis shows that some microRNAs downregulate large numbers of target mRNAs. Nature 433: 769-773.

Lu, J., Getz, G., Miska, E.A., Alvarez-Saavedra, E., Lamb, J., Peck, D., Sweet-Cordero, A., Ebert, B.L., Mak, R.H., Ferrando, A.A., et al. 2005. MicroRNA expression profiles classify human cancers. Nature 435: 834-838.

Mansfield, J.H., Harfe, B.D., Nissen, R., Obenauer, J., Srineel, J., Chaudhuri, A., Farzan-Kashani, R., Zuker, M., Pasquinelli, A.E., Ruvkun, G., et al. 2004. MicroRNA-responsive 'sensor' transgenes uncover Hox-like and other developmentally regulated patterns of vertebrate microRNA expression. Nat. Genet. 36: 1079-1083.

McFadden, D.G., Charite, J., Richardson, J.A., Srivastava, D., Firulli, A.B., and Olson, E.N. 2000. A GATA-dependent right ventricular enhancer controls dHAND transcription in the developing heart. Development 127: 5331-5341.

Meister, G., Landthaler, M., Dorsett, Y., and Tuschl, T. 2004. Sequence-specific inhibition of microRNA- and siRNA-induced RNA silencing. RNA 10: 544-550.

Poy, M.N., Eliasson, L., Krutzfeldt, J., Kuwajima, S., Ma, X., Macdonald, P.E., Pfeffer, S., Tuschl, T., Rajewsky, N., Rorsman, P., et al. 2004. A pancreatic islet-specific microRNA regulates insulin secretion. Nature 432: 226-230.

Reinhart, B.J., Slack, F.J., Basson, M., Pasquinelli, A.E., Bettinger, J.C., Rougvie, A.E., Horvitz, H.R., and Ruvkun, G. 2000. The 21-nucleotide let-7 RNA regulates developmental timing in Caenorhabditis elegans. Nature 403: 901-906.

Rhoades, M.W., Reinhart, B.J., Lim, L.P., Burge, C.B., Bartel, B., and Bartel, D.P. 2002. Prediction of plant microRNA targets. Cell 110: 513-520.

Sokol, N.S. and Ambros, V. 2005. Mesodermally expressed Drosophila microRNA-1 is regulated by Twist and is required in muscles during larval growth. Genes \& Dev. (this issue).

Stark, A., Brennecke, J., Russell, R.B., and Cohen, S.M. 2003. Identification of Drosophila MicroRNA Targets. PLOS Biol. 1: E60.

Wienholds, E., Kloosterman, W.P., Miska, E., Alvarez-Saavedra, E., Berezikov, E., de Bruijn, E., Horvitz, R.H., Kauppinen, S., and Plasterk, R.H. 2005. MicroRNA Expression in zebrafish embryonic development. Science 309: 310-311.

Wightman, B., Ha, I., and Ruvkun, G. 1993. Posttranscriptional regulation of the heterochronic gene lin-14 by lin- 4 mediates temporal pattern formation in C. elegans. Cell 75: 855-862.

Xie, X., Lu, J., Kulbokas, E.J., Golub, T.R., Mootha, V., LindbladToh, K., Lander, E.S., and Kellis, M. 2005. Systematic discovery of regulatory motifs in human promoters and $3^{\prime}$ UTRs by comparison of several mammals. Nature 434: 338 345.

Xu, P., Vernooy, S.Y., Guo, M., and Hay, B.A. 2003. The Drosophila microRNA Mir-14 suppresses cell death and is required for normal fat metabolism. Curr. Biol. 13: 790-795.

Zhao, Y., Samal, E., and Srivastava, D. 2005. Serum response factor regulates a muscle-specific microRNA that targets Hand2 during cardiogenesis. Nature 436: 214-220. 


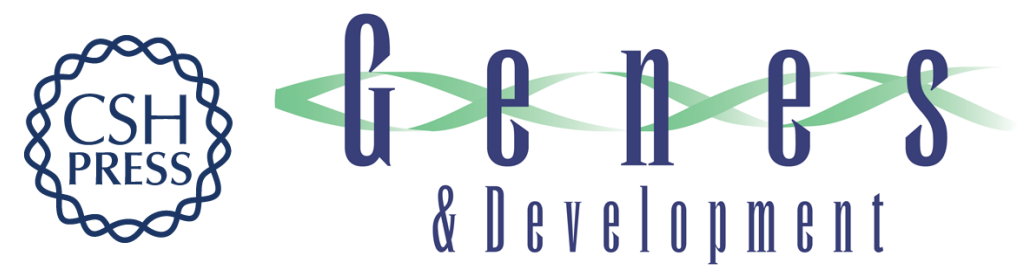

\section{Not miR-ly muscular: microRNAs and muscle development}

Julius Brennecke, Alexander Stark and Stephen M. Cohen

Genes Dev. 2005, 19:

Access the most recent version at doi:10.1101/gad.1363905

References This article cites 34 articles, 6 of which can be accessed free at: http://genesdev.cshlp.org/content/19/19/2261.full.html\#ref-list-1

License

Email Alerting Receive free email alerts when new articles cite this article - sign up in the box at the top Service right corner of the article or click here.

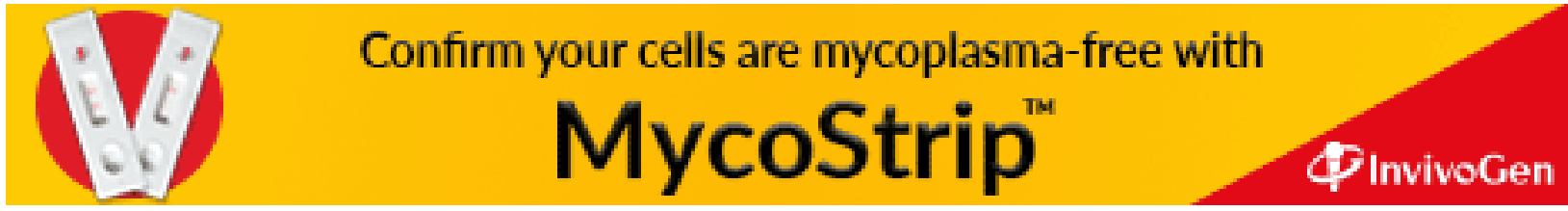

